\title{
Improvement the Lodging Resistance of Banana (Musa AAA)
}

\author{
Shu Haiyan ${ }^{1,2}$, Sun Wei ${ }^{1,2}$, Wu Zhengjing ${ }^{3}$ and Chang Shenghe* ${ }^{* 1,2}$ \\ ${ }^{1}$ Haikou experimental station, Chinese Academy of Tropical Agricultural Sciences, China \\ ${ }^{2}$ The key lab of Hainan banana genetics and breeding, China \\ ${ }^{3}$ School of Forestry, Henan University of Science and Technology, China
}

Received: 㭗 August 12, 2018; Published: 海 August 23, 2018

*Corresponding author: Chang Shenghe, Haikou experimental station, Chinese Academy of Tropical Agricultural Sciences, The key lab of Hainan banana genetics and breeding, china

\begin{abstract}
Banana is an important crop and fruit in many developing countries. China is one of the main banana-producing countries. China's banana production was always heavily affected by typhoon. The physical strength of banana pseudostem was mainly determined by the content of lignin. 4-coumarate: CoA ligase (4CL) is a rate-limiting enzyme for lignin synthesis. There were 25 4CL genes in banana A genome. Mu4CL15 was the main gene for encoding 4CL in banana pseudostem. The substrate that Mu4CL15 preferred can be ordered as the followed: 4-coumaric acid, caffeic acid, ferulic acid and sinapic acid from the most to the least. After Mu4CL15 was transformed into tobacco, the lignin content in the stem of the transgenic plant was significantly higher than that of the wild type. The stem strength of the transformed seedlings was higher than that of the wild type. After banana embryogenic suspension cells were transformed with Mu4CL15, the lignin content in pseudostem of the transformed plant was significantly higher than the control.

The physical strength of the transformed-plant pseudostem was also distinctly higher than the control. Enhancing banana plant's lodging resistance by transforming 4-coumarate: $\mathrm{CoA}$ ligase gene is feasible. Besides transgenic method, screening and identifying the germ plasm resource of banana can also breed new cultivars with higher resistance to lodging. Work on identifying and screening the physical strength of banana germ plasm pseudostem can be reduced by measuring seedling pseudostem diameter, total lignin and the expression of 4-coumarate: CoA ligase gene Mu4CL15. The breeding time can also be shorten by measuring these three characters. These researches lay a foundation for developing transgenic banana varieties with higher-lodging resistance.
\end{abstract}

Keywords: Banana (Musa AAA); Lodging Resistance; Lignin; 4-Coumarate: Coa Ligase(4CL)

\section{Introduction}

China ranks third in the world in terms of banana production. Chinese banana-planting areas belong to tropical monsoon climate region, which was always blown by typhoon in summer and autumn. When typhoon passed through, in many cases, banana plants were blown down and pseudostems were broken. Selecting dwarf mutants can reduce the loss to some extent. But decreasing plant height will lead to the reduction of photosynthesis, which will result that the final production is cut down. Cultivating new varieties with high-lodging resistance is a permanent solution to resolve this problem. Lodging resistance in crops is a quantitative trait controlled by multiple genes. Stem strength, the bending or breaking strength of the stem, is a key factor for plant lodging resistance [1]. The structural carbohydrates, lignin and cellulose, played key roles for plant stem strength [2]. Cellulose is soft and flexible. Lignin makes plant-tissue's mechanical intensity and supportable ability [2]. Plant's lodging resistance was mainly determined by lignin content in stem [3-5]. Decreasing the lignin content will make stem soft and fragile, resulting that crops lodged [6]. A small increase in lignin content will result in a high increase in stem strength and lodging resistance [2].
There were three kinds of lignin monomers in banana plant [7]. Only these three kinds of lignin monomers increased proportionally in stem cells, plant's lodging resistance will be enhanced. 4-coumarate: CoA ligase (4CL) is a rate-limiting enzyme for lignin synthesis [8]. Analyzing the relationship between 4CLs and plant-lodging resistance is important for finding candidate genes for constructing transgenic plants with high-lodging resistance. There were four genomes-A, B, S, and T- presently known in cultivated bananas. Most banana varieties cultivated in China were from Cavendish gerplasm, which harbored only A genome. Twenty-five 4CL-homologous sequences were found in banana A genome. Among these homologous genes, Mu4CL15 had the closest relationship with bmr2, a sorghum 4CL whose enzyme characteristics and crystal structure had been identified [9]. The substrate that Mu4CL15 preferred can be ordered as the following: 4-coumaric acid, caffeic acid, ferulic acid and sinapic acid from the most to the least [10]. Tobacco transformed with Mu4CL15 had higher lignin content and lodging resistance than the plants transformed with empty vector [10]. 
Over-expressing Mu4CL15 in plant can increase plant's lignin content and lodging resistance. After banana embryogenic suspension cells were transformed with Mu4CL15, the lignin content in the pseudostem of the transformed seedling was $10.3 \pm 0.6 \%$, while that value of the control was only $5.3 \pm 0.5 \%$ [11]. The lignin content in pseudostem of the transformed plant was significantly higher than that in pseudostem of the control [11]. The physical strength of the transformed-plant pseudostem was also distinctly higher than the control [11]. Enhancing banana plant's lodging resistance by transforming 4-coumarate: CoA ligase gene is feasible. Besides transgenic method, screening and identifying the germ plasm resource of banana can also breed new cultivars with higher resistance to lodging. The volume of mature banana plant was large. On average, an acre space can only accommodate 780 to 1080 banana plants. Getting a single plant with valuable trait always need to screen thousands of plants. Breeding new cultivars by screening mature-banana plants needs much hard work. If the physical strength of pseudostem of mature banana can be predicted in seedling stage, much labor and work can be cut. The spanning time of breeding can also be reduced. We found that the plant with high-physical strength in seedling stage always has high-physical strength in mature stage.

The physical strength of banana-seedling pseudostem was closely related to pseudostem diameter, total lignin and the expression of Mu4CL15 [12]. Pseudostem diameter, total lignin and the expression of Mu4CL15 can be used to predict the physical strength of banana pseudostem [12]. Work on identifying and screening the physical strength of banana germ plasm can be reduced by measuring seedling-pseudostem diameter, seedlingtotal lignin and the expression of Mu4CL15 in seedling pseudostem. The breeding-spanning time can also be shortened by measuring these three characters. These researches lay a foundation for developing banana varieties with higher-lodging resistance.

\section{Acknowledgement}

This work was supported by the Key Research and Developmental Plan Item of Hainan Province (No. ZDYF2018072).

\section{ISSN: 2574-1241}

DOI: 10.26717/BJSTR.2018.08.001631

Chang Shenghe. Biomed J Sci \& Tech Res

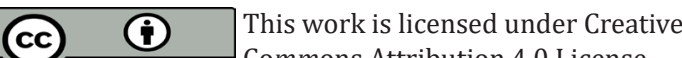
This work is licensed under Creative

Submission Link: https://biomedres.us/submit-manuscript.php

\section{References}

1. Wagner A, Donaldson L, Kim H, Phillips L, Flint H, et al. (2009) Suppression of 4-coumarate-coA ligase in the coniferous gymnosperm Pinus radiate. Plant Physiology 149: 370-383.

2. Ma QH (2009) The expression of caffeic acid 3- 0-methyltransferase in two wheat genotypes differing in lodging resistance. Journal of Experimental Botany 60(9): 2763-2771.

3. Jones L, Ennos AR, Turner SR (2001) Cloning and characterization of irregular xylem4 (irx4): a severely lignin-deficient mutant of Arabidopsis. Plant J 26: 205-216.

4. Ma QH, Xu Y, Lin ZB, He P (2002) Cloning of cDNA encoding COMT from wheat which is differentially expressed in lodging-sensitive and -resistant cultivars. Journal of Experimental Botany 53: 2281-2282.

5. Tanaka K, Murata K, Yamazaki M, Onosato K, Miyao A, et al. (2003) Three distinct rice cellulose synthase catalytic subunit genes required for cellulose synthesis in the secondary wall. Plant Physiol, 133: 73-83.

6. Halpin C, Holt K, Chojecki J, Oliver D, Chabbert B, et al. (1998) Brown-midrib maize (bm1): a mutation affecting the cinnamyl alcohol dehydrogenase gene. The Plant Journal 14: 545-553.

7. Oliveira L, Evtuguin D, Cordeiro N, Silvestre AJD (2009) Structural characterization of stalk lignin from banana plant. Industrial Crops \& Products 29(1): 86-95.

8. Baucher M, Halpin C, Petit-Conil M, Boerjan W (2003) Lignin: genetic engineering and impact on pulping. Crit Rev Biochem Mol Biol 38(4): 305-350.

9. Saballos A, Sattler SE, Sanchez E, Foster TP, Xin Z, et al. (2012) Brown midrib2 (Bmr2) encodes the major 4-coumarate: coenzyme A ligase involved in lignin biosynthesis in sorghum (Sorghum bicolor (L.) Moench). Plant Journal 70: 818-830.

10. Shu H, Sun W, Wei Q, Wang Z, Yin M, et al. (2017) Identification and Characterization of a Banana 4CL Gene Mu4CL15. Genomics and Applied Biology 8: 3025-3033.

11. Chang S, Sun W, Xu G, Wei Q Li J, Shu H, et al. (2017) Enhancing Lodging Resistance of Banana Plant by Transforming 4-coumarate: CoA Ligase Gene Mu4CL15. Molecular Plant Breeding 12: 4905-4911.

12. Chang S, Wu Z, Sun W, Qiao L, Zeng Q, et al. (2018) Factors related to physical strength of banana pseudostem. Advances in Bioscience and Biotechnology 9(4): 136-146.

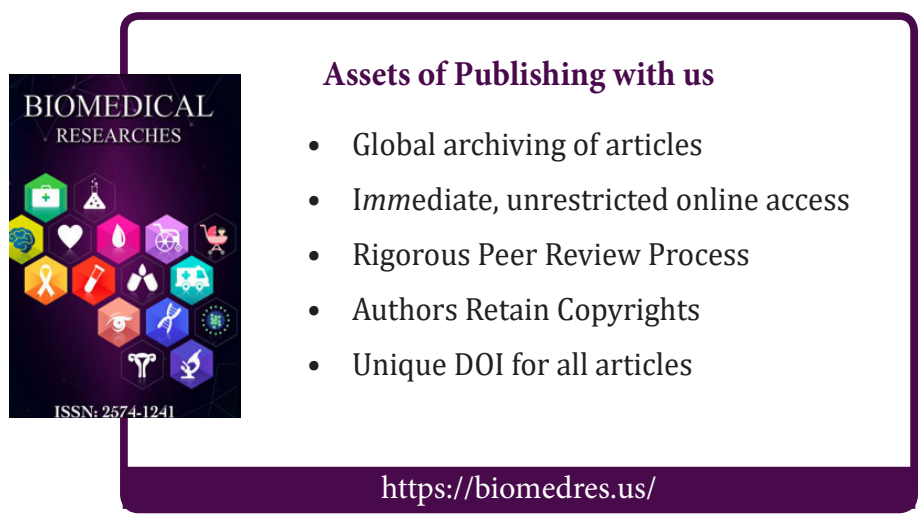

